\title{
Transoral Laser Microsurgery for Carcinoma in situ of the Glottic Larynx
}

\author{
A Retrospective Follow-Up Study
}

\author{
Ralph M.W. Roedel ${ }^{\mathrm{a}}$ Hans Christiansen $^{\mathrm{b}}$ Roland M. Mueller ${ }^{\mathrm{a}}$ \\ Christoph Matthias ${ }^{\mathrm{a}}$
}

Departments of a Otorhinolaryngology, Head and Neck Surgery, and ${ }^{\mathrm{b}}$ Radiotherapy and Radiooncology, University of Göttingen, Göttingen, Germany

\section{Key Words}

Larynx $\cdot$ Carcinoma, in situ - Early glottic cancer ·

Transoral laser microsurgery $\cdot$ Local control

\begin{abstract}
Background: To investigate long-term results of transoral $\mathrm{CO}_{2}$ laser microresection (TLM) in glottic carcinoma in situ (CIS). Methods: A retrospective study of 34 patients with glottic CIS treated initially with TLM between 1986 and 2004. Median post-operative follow-up time was 62 months. $\boldsymbol{R} \boldsymbol{e}$ sults: Three- and 5-year local control rates were 97 and 93\%, respectively. Four patients developed local recurrence (rTis, rTis, rT1, rT4) that could be salvaged by repeated TLM in all cases. Neither adjuvant radiotherapy nor open partial or total laryngectomy was performed. There was no tumour-related death in this series. Conclusion: TLM can be considered as an effective method in the treatment of glottic CIS not only for the primary therapy, but also in cases of local recurrence.

Copyright $\odot 2008$ S. Karger AG, Basel
\end{abstract}

\section{Introduction}

Carcinoma in situ (CIS) was first described by Broders [1] in 1932. On histological examination, CIS is characterized by atypical cells without penetration of the basal membrane and without metastatic potential, and is therefore considered as an early neoplastic disease.

CIS of the larynx is most frequently located at the true vocal cords. At this site, hoarseness is the first symptom in the majority of cases and it may be detected before it becomes invasive, whereas manifestation at the supra- or subglottic region appears clinically occult due to a lack of symptoms before the superficial lesion progresses to invasive carcinoma. In contrast to invasive glottic cancer, the extension of glottic CIS is not reflected by T-stage, as CIS of the true vocal cords may range from small and limited tumours involving only a small portion of 1 vocal cord to extended lesions comprising both vocal cords, with or without involvement of the anterior commissure and/or the arytenoid.

With regard to voice preservation and due to a possible multifocal appearance of the lesions, primary radiotherapy has been advocated as a preferred treatment modality. In cases of recurrence, however, total laryngectomy is often needed as a salvage procedure after failure of primary radiotherapy of early glottic cancer [2-4], which 
means a reduced quality of life for the patient. Organ-preserving transoral $\mathrm{CO}_{2}$ laser microresection (TLM) of early glottic cancer has been introduced as an oncologically safe and cost-effective therapeutic option [5, 6]. However, with regard to laryngeal CIS, only few data on long-term follow-up are available. Therefore, it was the aim of the present study to investigate the long-term results of TLM for the treatment of CIS of the larynx on a greater cohort of patients.

\section{Patients and Methods}

\section{Patients}

Thirty-six patients with previously untreated glottic CIS were treated with TLM between August 1986 and December 2004 at the Department of Otorhinolaryngology, University of Göttingen, Germany, by various surgeons. This represents $8 \%$ of all early glottic malignancies treated at our institution over the same time span. Two male patients were lost to follow-up, and were excluded from the study. The remaining 34 patients ranged in age from 22 to 87 years (median age, 64 years); 29 were men and 5 were women. Median post-therapeutic follow-up time was 62 months (range, 13-225 months).

\section{Pre-Operative Examination}

The routine pre-operative examination comprised magnifying laryngoscopy and phoniatric video stroboscopy. In 13 patients (38\%), CIS was already proved by previous punch biopsy. Twentyone patients (62\%) presented with a vocal cord lesion suspicious of early glottic cancer, but without a pre-operative biopsy or with negative pre-operative histopathological results. Panendoscopy for the exclusion of a second primary tumour was done together with the tumour resection.

\section{Treatment of Primary Tumours}

In most patients, partial cordectomy was the preferred treatment modality comprising resection of the epithelium, Reinke's space, and at least the medial portion of the vocal ligament in order to estimate a possible microinvasion.

In cases with circumscribed lesions up to about $5 \mathrm{~mm}$ and without anterior commissure involvement (7 patients, 21\%), an excisional biopsy was performed with complete removal of all macroscopic disease in 1 piece, followed by permanent histopathological examination. For more extended tumours and/or in cases with anterior commissure involvement (27 patients, 79\%), the entire lesion was excised - if necessary, in 2 or more pieces - with individually adapted resection margins, followed by permanent histological examination in order to establish the final diagnosis. In cases without pre-operative biopsy or with negative pre-operative histopathological results, CIS was confirmed by surgery on frozen sections.

No patient had adjuvant radiotherapy after initial surgery. Involvement of the anterior commissure (AC) was histopathologically confirmed in 3 patients (9\%). Regular swabbing of fibrin layers was performed in 1 patient $(3 \%)$ in order to prevent glottic synechia.
Statistical Analysis

Postoperative follow-up data could be evaluated for all patients. Each patient was followed until death or at the longest until March 2006. A local recurrence was defined as a carcinoma in situ or a carcinoma occurring after completion of primary treatment, independent of the localization in the larynx. Local control was defined as complete and continuous disappearance of disease at the primary site. Local control and overall survival rates were calculated by the Kaplan-Meier method [7].

\section{Results}

\section{Re-Resection}

One patient (3\%) received re-resection because of uncertain resection margins, but the re-resection specimens were free of tumour. Another 5 patients (15\%) had a second microlaryngoscopy because of granuloma, webs or scar formation in order to exclude recurrence. All specimens from these patients were free of tumour.

\section{Locoregional Control}

Four of the 34 patients (12\%) developed local or locoregional recurrences with an average interval to recurrence of 67 months (table 1). One of these patients had primary $\mathrm{AC}$ involvement, whereas the $\mathrm{AC}$ was free of tumour in the other 3 cases at the time of primary surgery. The 3and 5-year local control rates were 97 and 93\%, respectively (fig. 1).

\section{Larynx Preservation and Ultimate Local Control}

All 4 recurrence patients had organ preserving salvage therapy carried out by up to 2 further laser resections. No patient had salvage laryngectomy. Thus, the ultimate local control was $100 \%$ by laser surgery alone.

\section{Second Primary Tumours}

Second primary tumours occurred in 4 patients (12\%) in: the pancreas, the rectum, the prostate and a lung.

\section{Survival}

Seven patients (21\%) died during follow-up, which lasted until March 2006. All patients died from intercurrent disease or second primary tumour. The 3- and 5-year overall survival rates were 93 and $82 \%$, respectively.

\section{Post-Operative Complications}

Only 1 patient (3\%) developed temporary endolaryngeal oedema, and was treated with corticosteroids. Major complications requiring surgical intervention were not observed. 
Table 1. Carcinoma in situ of the glottis: clinical data of the recurrence patients

\begin{tabular}{llllllll}
\hline $\begin{array}{l}\text { Patient } \\
\text { No. }\end{array}$ & $\begin{array}{l}\text { Age at diag- } \\
\text { nosis, years }\end{array}$ & $\begin{array}{l}\text { Glottic } \\
\text { site }\end{array}$ & $\begin{array}{l}\text { Total follow- } \\
\text { up, months }\end{array}$ & $\begin{array}{l}\text { Time to (first) re- } \\
\text { currence, months }\end{array}$ & T-stage & Salvage & $\begin{array}{l}\text { Out- } \\
\text { come }\end{array}$ \\
\hline 1 & 49 & right & 107 & 9 & rT1N0M0 & TLM & AFD \\
2 & 70 & left & 90 & 37 & rTis & 2 × TLM & AFD \\
3 & 64 & left, AC & 225 & 196 & rT4N1M0 & TLM and ND & AFD ${ }^{1}$ \\
4 & 64 & both & 141 & 73 & rTis & TLM & AFD \\
\hline
\end{tabular}

$\mathrm{TLM}=$ Transoral laser microresection; $\mathrm{ND}=$ neck dissection; $\mathrm{AC}=$ anterior commissure; $\mathrm{AFD}=$ alive and free of disease.

${ }^{1}$ The patient developed a second primary in the prostate.

\section{Voice Quality}

After initial TLM, good voice quality was retained in 26 patients (76\%). Permanent hoarseness was noticeable in 8 patients (24\%); among them were 2 of the 4 recurrence patients (patient No. 1 and 2; table 1), who needed further laser resection. As this was a retrospective review focussed predominantly on the oncological outcome of glottic CIS after TLM, voice quality was not investigated systematically by objective measurement.

\section{Discussion}

There is still an ongoing debate about the adequate treatment of CIS of the true vocal cords. Primary radiotherapy has been advocated as a successful and effective method of non-invasive treatment, especially with regard to favourable functional results. Data on local control have risen up to $100 \%$ with a weighted average of about 85-90\% (see Garcia-Serra et al. [8] and Sadri et al. [9] for detailed overview). Despite these advantages, radiotherapy is a time-consuming procedure lasting several weeks and its repetition in case of recurrence or a second primary tumour in the region of irradiation poses difficulties. For early glottic cancer, the incidence of major or long-term complications due to primary radiotherapy, such as glottic fibrosis and/or stenosis, cervical myelitis, laryngeal cartilage necrosis and hypothyroidism may be low, whereas minor complications, such as laryngitis or moderate oedema, are reported to occur in up to $18 \%$ of patients [10-12]. Delayed diagnosis of persistent or recurrent tumour may be due to residual oedema. Irradiation includes the need for a diagnostic microlaryngoscopy with biopsy, a procedure that can be used for curative surgery, especially in case of a circumscribed lesion [13].

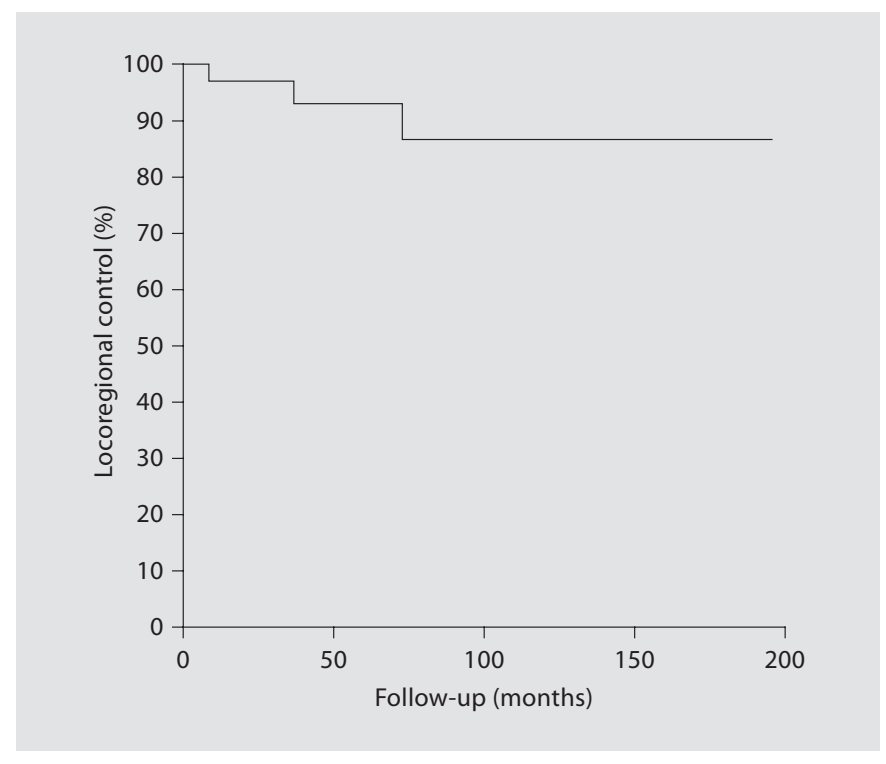

Fig. 1. Kaplan-Meier estimate of locoregional control of our 34 patients with glottic carcinoma in situ treated by TLM.

For reliable diagnosis of CIS, histological examination not only of some random punch biopsy specimens but of the entire lesion should be performed $[14,15]$. Thus, primary radiotherapy has potential to understage the lesion due to the fact that the 'in situ' lesion may actually harbour invasive carcinoma at other sites where a biopsy was not taken and these tumours remain classified as 'Tis' after irradiation [16]. In our opinion, primary radiotherapy may be preferred in cases of extended CIS lesions when severe functional problems have to be expected after surgery. Furthermore, irradiation may be recommended as an organ-preserving option for cases of surgi- 
Table 2. TLM literature review for glottic carcinoma in situ

\begin{tabular}{lllll}
\hline Series & $\begin{array}{l}\text { Num- } \\
\text { ber of } \\
\text { pa- } \\
\text { tients }\end{array}$ & $\begin{array}{l}\text { Local control } \\
\text { with initial } \\
\mathrm{CO}_{2} \text { laser } \\
\text { treatment }^{1}, \%\end{array}$ & $\begin{array}{l}\text { Ultimate } \\
\text { local } \\
\text { control, } \\
\%\end{array}$ & $\begin{array}{l}\text { Larynx } \\
\text { preserva- } \\
\text { tion, \% }\end{array}$ \\
\hline Damm et al. [19] & 29 & 86 & 100 & 100 \\
Moreau [16] & 26 & 96 & 100 & 100 \\
Le et al. [18] & 11 & 80 & 100 & n.r. \\
Peretti et al. [20] & 13 & 92 & 100 & 92 \\
De Monès et al. [15] & 12 & 75 & 100 & 100 \\
Pradhan et al. [21] & 21 & 86 & 100 & 95 \\
Mortuaire et al. [22] & 21 & 100 & 100 & 100 \\
Ledda and Puxeddu [23] & 14 & 100 & 100 & 100 \\
Sigston et al. [24] & 16 & 81 & 100 & 100 \\
Hartl et al. [25] & 21 & 76 & 100 & 95 \\
Present Study & 34 & $93^{2}$ & 100 & 100 \\
& & & &
\end{tabular}

n.r. $=$ Not reported.

${ }^{1}$ Including local recurrences with invasive disease and/or carcinoma in situ (rTis).

25 -year local control rate according to Kaplan-Meier.

cal failure and/or in patients at a high risk of general anaesthesia complications.

Given the disadvantages of primary radiotherapy, surgery has been advocated for the treatment of CIS. In our opinion, complete cordectomy and open procedures, such as partial or total laryngectomy, represent an overtreatment in cases of glottic CIS and are often followed by unfavourable functional results. Thus, these procedures may be reserved for salvage therapy or for patients with inadequate endoscopic exposure. Microflap excision has been introduced as a technique allowing precise microscopic control of the area of resection with regard to local control, mucosal preservation and functional results. It is performed by making an incision adjacent to the lesion with elevation of the deep layer of the lamina propria and excision. In a series by Schweinfurth et al. [17], only 1 of 20 patients presenting with severe dysplasia or CIS progressed to invasive carcinoma. However, there are no further studies available on a greater cohort of patients treated by this modality.

Other opinions in primary surgical therapy for glottic CIS include vocal cord stripping. According to Le et al. [18], local recurrence is frequent with stripping alone. In their series of 15 patients treated with vocal cord stripping, 5- and 10-year local control rates were both only $56 \%$. A detailed literature review [8] revealed a weighted average of only $72 \%$ for local control obtained by stripping alone, and an ultimate local control of approximate- ly $92 \%$ including radiotherapy and open surgical procedures for salvage.

In recent years, organ-preserving TLM of laryngeal tumours has achieved considerable popularity. In contrast to endoscopic resection with cold instruments, the lack of superficial bleeding represents a considerable advantage for the surgeon to control surgical margins; thus, enabling resections well adapted to the tumour size. Haemostasis in the form of conventional electro coagulation is not necessary in the majority of cases. As modern lasers allow dissection with very little carbonization, tissue can be spared, which results in a better functional outcome. In comparison to other treatment options, TLM offers a shorter duration of treatment and hospitalization. It can be performed as an outpatient procedure preserving the option of repeated TLM, radiotherapy, and, if necessary, salvage (open) surgery. A tracheotomy is usually not necessary. Each excision can be adapted individually to the size of the tumour allowing the establishment of final diagnosis and therapy at the same time. For glottic CIS, data reported on local control vary between 76 and $100 \%$ with larynx preservation in more than $92 \%$ of cases $[15$, 16, 18-25] (table 2). In the present series, our data on local control confirm the favourable results obtained in previous studies recommending TLM as the method of choice in cases of glottic CIS when endoscopic exposition poses no greater difficulties to the surgeon. In comparison with our previous study on invasive early glottic cancer [6], we failed to confirm that glottic CIS recur more frequently than in cases with small infiltrative carcinoma [13].

Involvement of the $\mathrm{AC}$ has been associated with poorer initial local control and larynx preservation, particularly in surgically treated patients $[14,18]$. In our series, the impact of AC involvement on local control could not be investigated as the lesion extended into the AC only in 3 cases. Only 1 of these patients developed locoregional recurrence (rT4N1) after a period of 196 months (16.3 years), which could be successfully treated by further laser resection and neck dissection despite the fact that adjuvant radiotherapy was refused. However, due to the long time interval, this tumour should be better considered as a second primary tumour.

With regard to the quality of the post-treatment voice, laser vaporization with/or without additional TLM has been introduced as a further treatment option for selected cases of glottic CIS [26]. However, as the possibility of histopathologically examining the total lesion is lost with this procedure, it carries the risk of understaging and undertreating a true invasive carcinoma, resulting in an unfavourable oncological outcome. 
As this is a retrospective study, data on objective measurement of vocal function could not be provided; however, our observations on post-operative assessment of voice quality confirm the results described in the literature after TLM for early glottic cancer, which seem to be similar to those after primary radiotherapy and are practically without phonatory change compared with the individual patient's vocal ability before surgery in the majority of cases $[5,19,27]$.

\section{Conclusion}

The present study supports the role of TLM in treating CIS of the larynx. Results on local control are similar to those obtained by primary radiotherapy. In cases of recurrence, organ-preserving surgery seems possible by repeated TLM, retaining all other treatment options, such as irradiation and open salvage procedures.

\section{References}

1 Broders AC: Carcinoma in situ contrasted with benign penetrating epithelium. JAMA 1932;99:1670-1674

-2 Viani L, Stell PM, Dalby JE: Recurrence after radiotherapy for glottic carcinoma. Cancer 1991;67:577-584

3 Ganly I, Patel SG, Matsuo J, Singh B, Kraus $\mathrm{DH}$, Boyle JO, Wong RJ, Shaha AR, Lee N, Shah JP: Results of surgical salvage after failure of definitive radiation therapy for earlystage squamous cell carcinoma of the glottic larynx. Arch Otolaryngol Head Neck Surg 2006;132:59-66.

$\checkmark 4$ Holsinger FC, Funk E, Roberts DB, Diaz EM: Conservation laryngeal surgery versus tota laryngectomy for radiation failure in laryngeal cancer. Head Neck 2006;28:779-784.

5 Brandenburg JH: Laser cordotomy versus radiotherapy: an objective cost analysis. Ann Otol Rhinol Laryngol 2001;110:312-318.

-6 Steiner W, Ambrosch P, Roedel RMW, Kron $\mathrm{M}$ : Impact of anterior commissure involvement on local control of early glottic carcinoma treated by laser microresection. Laryngoscope 2004; 114:1485-1491.

7 Kaplan EL, Meier P: Nonparametric estimation from incomplete observations. J Am Stat Assoc 1958;58:301-305.

$\checkmark 8$ Garcia-Serra A, Hinerman RW, Amdur RJ, Morris CG, Mendenhall WM: Radiotherapy for carcinoma in situ of the true vocal cords. Head Neck 2002;24:390-394.

$\checkmark 9$ Sadri M, McMahon J, Parker A: Management of laryngeal dysplasia: a review. Eur Arch Otorhinolaryngol 2006;263:843-852.

$\checkmark 10$ Mantravadi RVP, Liebner EJ, Haas RE, Skolnik EM, Applebaum EL: Cancer of the glottis: prognostic factors in radiation therapy. Radiology 1983;149:311-314.
Chatany M, Matayoshi Y, Masaki N: Radiation therapy for larynx carcinoma: longterm results of stage I glottic carcinoma. Strahlenther Onkol 1993;169:102-106.

12 Bron LP, Soldati D, Zouhair A, Ozsahin M, Brossard E, Monnier P, Pasche P: Treatment of early stage squamous-cell carcinoma of the glottic larynx: endoscopic surgery or cricohyoidoepiglottopexy versus radiotherapy. Head Neck 2001;23:823-829.

13 Eckel HE, Raunik W, Rogatsch H: Laryngea intraepithelial neoplasia (carcinoma in situ of the larynx). Laryngorhinootologie 2008; 87:425-442.

14 Myssiorek D, Vambutas A, Abramson AL: Carcinoma in situ of the glottic larynx. Laryngoscope 1994;104:463-467.

15 De Monès E, Hans S, Hartl DM, Laccoureye O, Brasnu D: Microchirurgie par voie endoscopique au laser $\mathrm{CO}_{2}$ des carcinomes in situ glottiques. Ann Otolaryngol Chir Cervicofac 2002;119:21-30.

16 Moreau PR: Treatment of laryngeal carcinomas by laser endoscopic microsurgery. Laryngoscope 2000;110:1000-1006.

-17 Schweinfurth JM, Powitzky E, Ossoff RH: Regression of laryngeal dysplasia after serial microflap excision. Ann Otol Rhinol Laryngol 2001;110:811-814.

$>18$ Le QT, Takamiya R, Shu HK, Smitt M, Singer M, Terris DJ, Fee WE, Goffinet DR, Fu KK: Treatment results of carcinoma in situ of the glottis: an analysis of 82 cases. Arch Otolaryngol Head Neck Surg 2000;126: 1305-1312.

-19 Damm M, Sittel C, Streppel M, Eckel HE: Transoral $\mathrm{CO}_{2}$ laser for surgical management of glottic carcinoma in situ. Laryngoscope 2000;110:1215-1221.
20 Peretti G, Nicolai P, Piazza C, Redaelli de Zinis LO, Valentini S, Antonelli AR: Oncological results of endoscopic resections of TIS and $\mathrm{T} 1$ glottic carcinomas by carbon dioxide laser. Ann Otol Rhinol Laryngol 2001;110: 820-826.

21 Pradhan SA, Pai PS, Neeli SI, D’Cruz AK: Transoral laser surgery for early glottic cancers. Arch Otolaryngol Head Neck Surg 2003;129:623-625.

22 Mortuaire G, Francois J, Wiel E, Chevalier D: Local recurrence after $\mathrm{CO}_{2}$ laser cordectomy for early glottic carcinoma. Laryngoscope 2006;116:101-105.

23 Ledda GP, Puxeddu R: Carbon dioxide laser microsurgery for early glottic carcinoma. Otolaryngol Head Neck Surg 2006;134:911915.

24 Sigston E, de Monès E, Babin E, Hans S, Hartl DM, Clement P, Brasnu DF: Earlystage glottic cancer: oncological results and margins in laser cordectomy. Arch Otolaryngol Head Neck Surg 2006;132:147-152.

25 Hartl DM, de Monès E, Hans S, Janot F, Brasnu D: Treatment of early-stage glottic cancer by transoral laser resection. Ann Otol Rhinol Laryngol 2007;116:832-836.

26 Mahieu HF, Patel P, Annyas AA, van der Laan T: Carbon dioxide laser vaporization in early glottic carcinoma. Arch Otolaryngol Head Neck Surg 1994;120:383-387.

27 Leirens J, Vidts G, Schmelzer B, della Faille D, Katz S, van Cauwenberge P: Premalignant lesions of the vocal cords: a retrospective study of 62 cases treated with $\mathrm{CO}_{2}$ laser. Acta Otololaryngol (Stockh) 1997;117:903-908. 